\title{
DISCUSSION PAPER: EVOLUTION OF LARYNGEAL FOLDING*
}

\author{
B. R. Fink, $\uparrow$ E. L. Frederickson, $\ddagger$ C. Gans, $\S$ and S. E. Huggins \\ $\dagger$ Department of Anesthesiology, University of Washington \\ Seattle, Washington 98195 \\ $\ddagger$ Department of Anesthesiology, Emory University \\ Atlanta, Georgia 30322 \\ $\S$ Department of Zoology, University of Michigan \\ Ann Arbor, Michigan 48104 \\ TDepartment of Biology, University of Houston \\ Houston, Texas 77004
}

\section{Evolution of LaRyngeal. Folding}

Conventionally, the larynx is thought to have evolved as a sphincteric valve operated by dilatator and constrictor muscular girdles.' It is believed that the primary design for protection was supplemented by modifications for olfaction (the epiglottis, supposedly degenerate in man), for respiration (optimal length of arytenoids, allegedly seven tenths of the diameter of the glottis; laryngeal air sacs), for deglutition (aryepiglottic folds; cuneiform cartilages), for regulation of intrathoracic pressure (inlet valve), for regulation of intraabdominal pressure (outlet valve), and for phonation (shortened arytenoid cartilages).

The conventional views, founded principally on comparative morphology, have become difficult to support in the light of dynamic studies. ${ }^{2}$ From considerations outlined below it seems likely that the human larynx evolved as a folding mechanism. Taken in phylogenetic sequence, its components seem to have developed adaptively to augmented yet protected ventilatory exchange, and, in mammals, to phonation, in primates, to arboreoterrestrial habitat, and, in man to orthograde work efforts and tonal, amplitudinal, and formant variety in speech.

The motion picture we are exhibiting shows the behavior of the glottis during respiration in various land vertebrates. It was photographed with an Olympus fiberoptic laryngoscope and a super $8-\mathrm{mm}$ Beaulieu camera at 18 feet per second. Unfortunately, a limited light source and the inverse square law make illumination uneven and inadequate for reproduction in print.

It is, of course, uncertain how closely any modern larynx resembles its taxal ancestors. In the frog, the laryngeal skeleton consists of a cricoid ring surmounted by half-dome-like arytenoids; a synovial articulation between the cricoid and the arytenoid is lacking. In a dead bullfrog the larynx remains closed (FIGURE 1). Furthermore, it closes spontaneously after an externally imposed opening force is released. One may conclude that this amphibian's larynx is endowed with springs that maintain the orad orifice shut. In the living animal the closed larynx is opened for respiration (FIGURE 2) by outward motion of the top of the half dome, hinged (unfolded) at the cricoarytenoid junction. Cartilaginous vocal shelves project medially from the arytenoids and remain roughly parallel during the open phase. The slitlike gap between them is the narrowest part of the open larynx and forms a primitive "glottis." The mechanism of opening constitutes a simple type of unfolding.

*Supported by grant HD085II, National Institute of Child Heath and Human Development United States Public Health Service. 

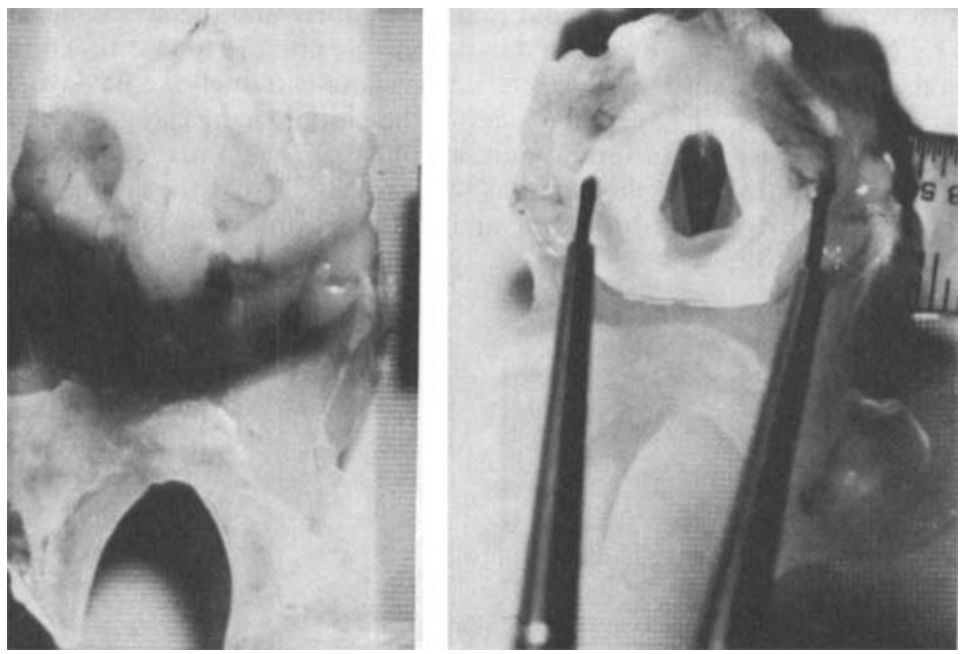

FIGIRE: 1. Excised bullfrog larynx. Left: closed. Right: opened artificially. Lower scale: millimeters.

In living unanesthetized reptiles exemplified by the boa constrictor, snapping turtle, Varanus lizard, and caiman, the buccal orifice of the larynx is predominantly closed and relatively briefly opened for ventilation, as first observed, in anesthetized Alligator mississippiensis, by Boelaert. ${ }^{3}$ In the living caiman, the anterosuperior end of the aryte-oid is connected by a fold to the hyoid (hyoarytenoid fold). There is
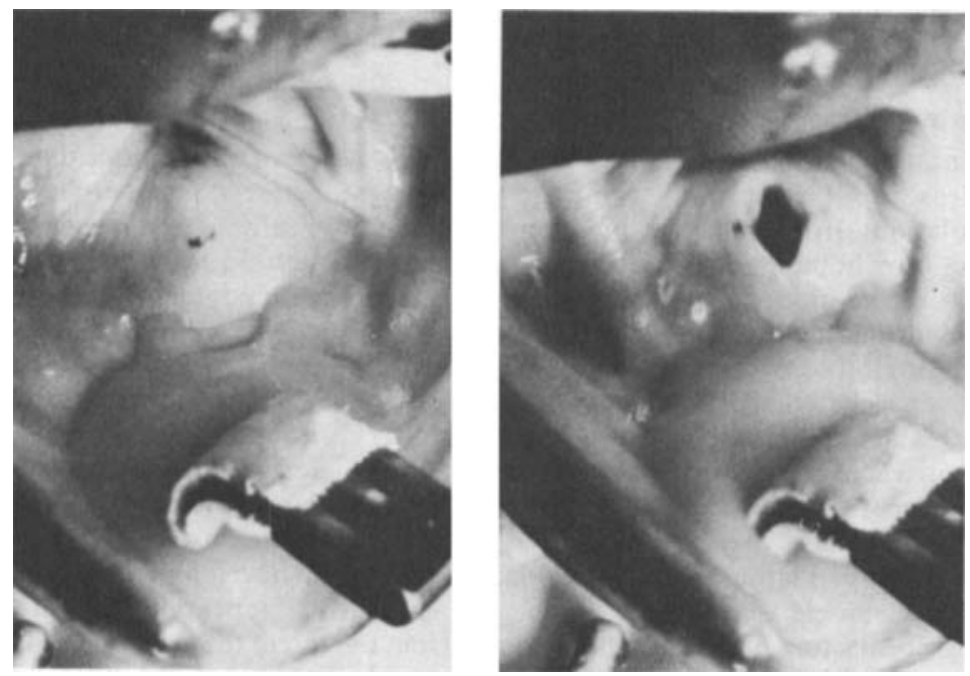

FigURE 2. Living bullfrog. Lefi: larynx closed. Right: larynx open in respiration. 
reported to be a synovial cricoarytenoid joint posteriorly and the larynx appears to be open by outward rotation of the arytenoid on this pivot (FIGURE 3). The action produces a quadrilateral entrance orifice, leading into a funnel-like passage, and a triangular exit or glottis. The apex and sides of the glottal triangle are formed by the arytenoids and the base by an interarytenoid fold that the animal can maintain at several different lengths. The photographs clearly suggest that the caiman's larynx makes increased provision for unfolding and increased provision for protection, as compared with the frog's.
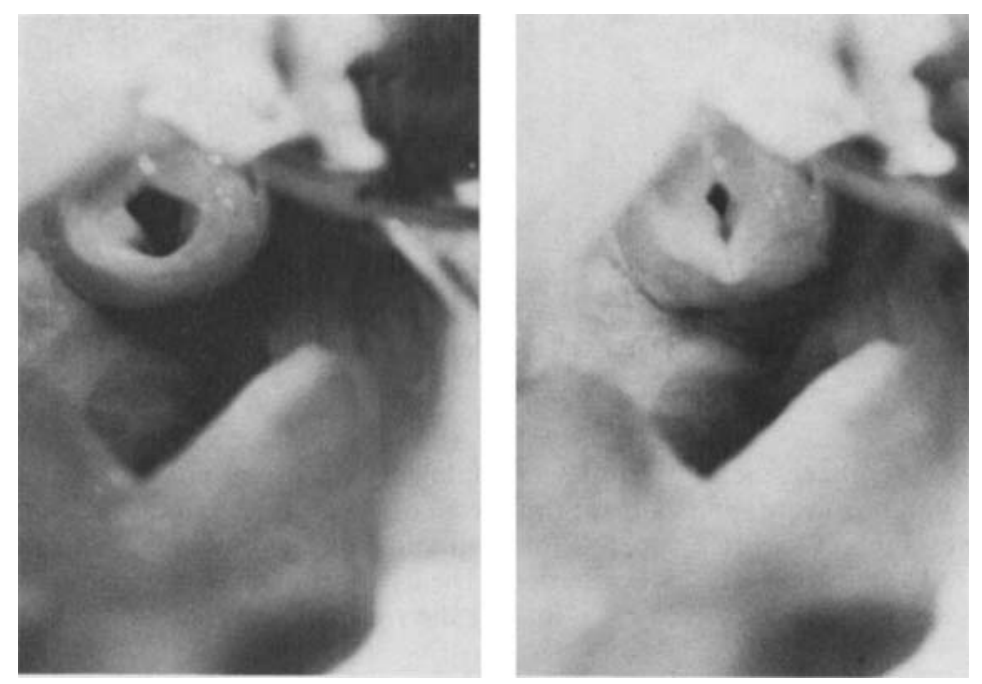

FIGURE 3. Living caiman. Left: early phase of opening of larynx in respiration. Right: late phase of opening of larynx: same magnification as FIGURE 1.

Monotreme and marsupial larynges have as yet not been photographed in action, and ideas about their mechanism are therefore still based on anatomy and on extrapolations from behavior in other taxa. Anatomically, a monotreme larynx (FIGURE 4) is notable for possessing the elements of a thyroid cartilage. Though the elements are unfused, they give attachment to a thyroarytenoid fold on each side. The , addition of the thyroarytenoid folds results in a quadrangular glottic opening and an increase in glottic conductance, as compared with the triangular "glottic" passage in the caiman. The enlargement, however, increases the threat of invasion by foreign material, and explains the presence of an epiglottis, also a monotreme innovation, as a protective covering. It is often stated that the epiglottis primarily subserves the sense of smell, by enabling deglutition to be carried out even while respiration continues, ${ }^{\prime}$ but no experimental support for this conjecture has yet emerged.

The marsupial larynx presents two major anatomical developments: fusion of the thyroid skeletal elements into a single cartilage and the appearance of corniculate cartilages projecting backward and medially from the top of the arytenoids. The onepiece thyroid cartilage is, in effect, a spring enfolding the glottis, and together with the corniculates maintains the glottis open except when the glottis is actively closed. 
Fink et al.: Discussion Paper

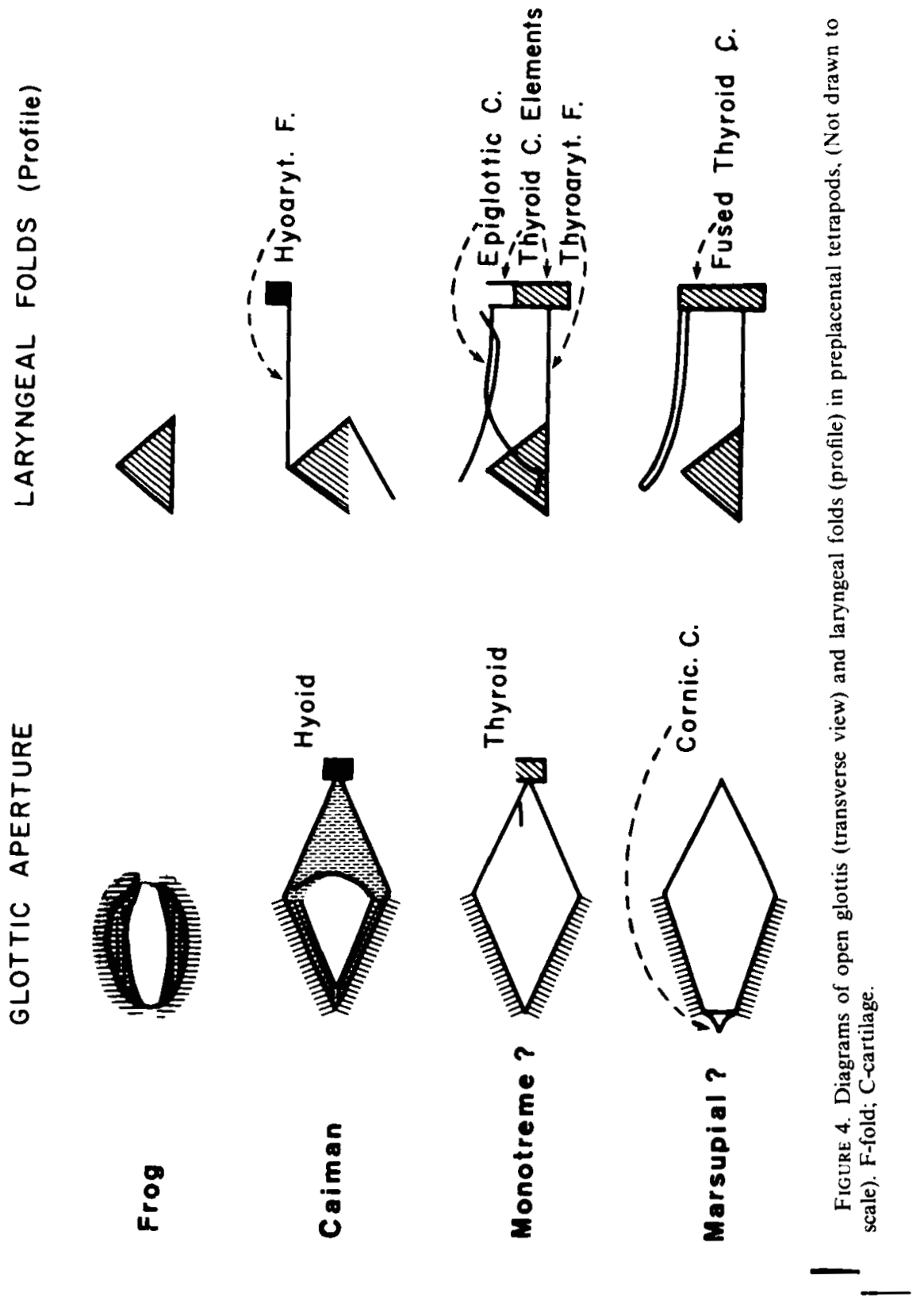


In so doing, these new developments bring about a further improvement in mean laryngeal conductance.

Laryngeal folding and unfolding ("plication") has evolved further in many placental mammals, though not to the same extent in all orders. In carnivora such as the dog and the cat the thyroarytenoid fold is found subdivided into cranial vestibular and caudal vocal portions (FIGURE 4), indistinctly separated by a ventricle. The upper fold is a specialization for protective closure, since it can be adducted and apposed to the epiglottis; it is ordinarily maintained in a far lateral, conductant position by a spring system based on the cuneiform cartilage, a cartilage encountered only in placental mammals. The lower fold, the vocal fold, is nearer the midline; it is specialized for phonation, and allows intermittent vibratory obstruction of the passage and the generation of sound.

The anthropoid primates manifest considerable additional evolution of laryngeal folding, notably of the epiglottic cartilage and the tissue anterior to its base (FIGURE 5). These structures form a veritable transverse median thyrohyoid fold in the anterior wall of the laryngeal entrance and can undergo several degrees of plication. In man, as one of us has shown, ${ }^{2}$ the median thyrohyoid tissue tends to become unfolded, elongated, and attenuated during inspiratory descent of the larynx, thereby enlarging the entrance anteroposteriorly. Conversely, it becomes folded. shortened vertically, and thickened anteroposteriorly during ascent with expiration or effort closure, and its top folds down backward protectively in swallow closure. It has also been shown that in man the vertical movements of the larynx are mechanically coupled to the transverse movements of the arytenoids, and that descent of the larynx probably provides the principal force for transverse separation of the laryngeal folds during inspiration. Mechanical coupling is dependent on a particular shape and orientation of the cricoarytenoid facets, and since the shape and orientation of the facets in many present-day nonhuman anthropoidea ${ }^{4}$ is known to be similar to those in man, it is reasonable to surmise that mechanical coupling of the vertical and transverse excursions occurs throughout the anthropoid suborder. Such coupling effects separation and approximation of the arytenoid vocal processes in parallel (somewhat like the folds in an accordion) instead of by rotation as in the cat, and converts the quadrilateral or narrowly pentagonal glottic aperture of other mammals into a widely pentagonal one. One may infer a related further reduction of respiratory flow resistance, or, reciprocally, a corresponding increase in laryngeal ventilatory conductance. The progressively lower station of the larynx in the series Lemur. Macacus, Pan, Homo, noted by Jordan, ${ }^{5}$ implies increasing vertical mobility of the organ compatible with the operation of the mechanical coupling system.

Some of the anthropoidea present modifications of the median thyrohyoid fold that may be adaptive to their habitat. In Macacus a preepiglottic subhyoid air sac is present. According to a recently formulated hypothesis ${ }^{2}$ the sac represents a spring that enables the larynx to close elastically in the execution of arboreal brachiation efforts. In the great apes and man the median air sac is absent, its place being taken by solid preepiglottic tissue bounded by elastic ligaments, and the epiglottic cartilage exhibits two distinct zones of folding: an upper pharyngeal part, the epiglottis, free standing and freely flexible, and a lower intralaryngeal or thyrohyoid portion, the epiglottic tubercle, whose flexibility is constrained by the preepiglottic median thyrohyoid tissue; the lower portion is nevertheless able to bend and unbend--to fold and unfold-in accommodation to changes in thyrohyoid approximation and separation.

In the apes the preepiglottic tissue may well function as a solid backing for checkvalve action of the flap-like vestibular folds, such as has been hypothesized by various authors ${ }^{3,6}$ to occur in man. Such action would facilitate the execution of brachial and 


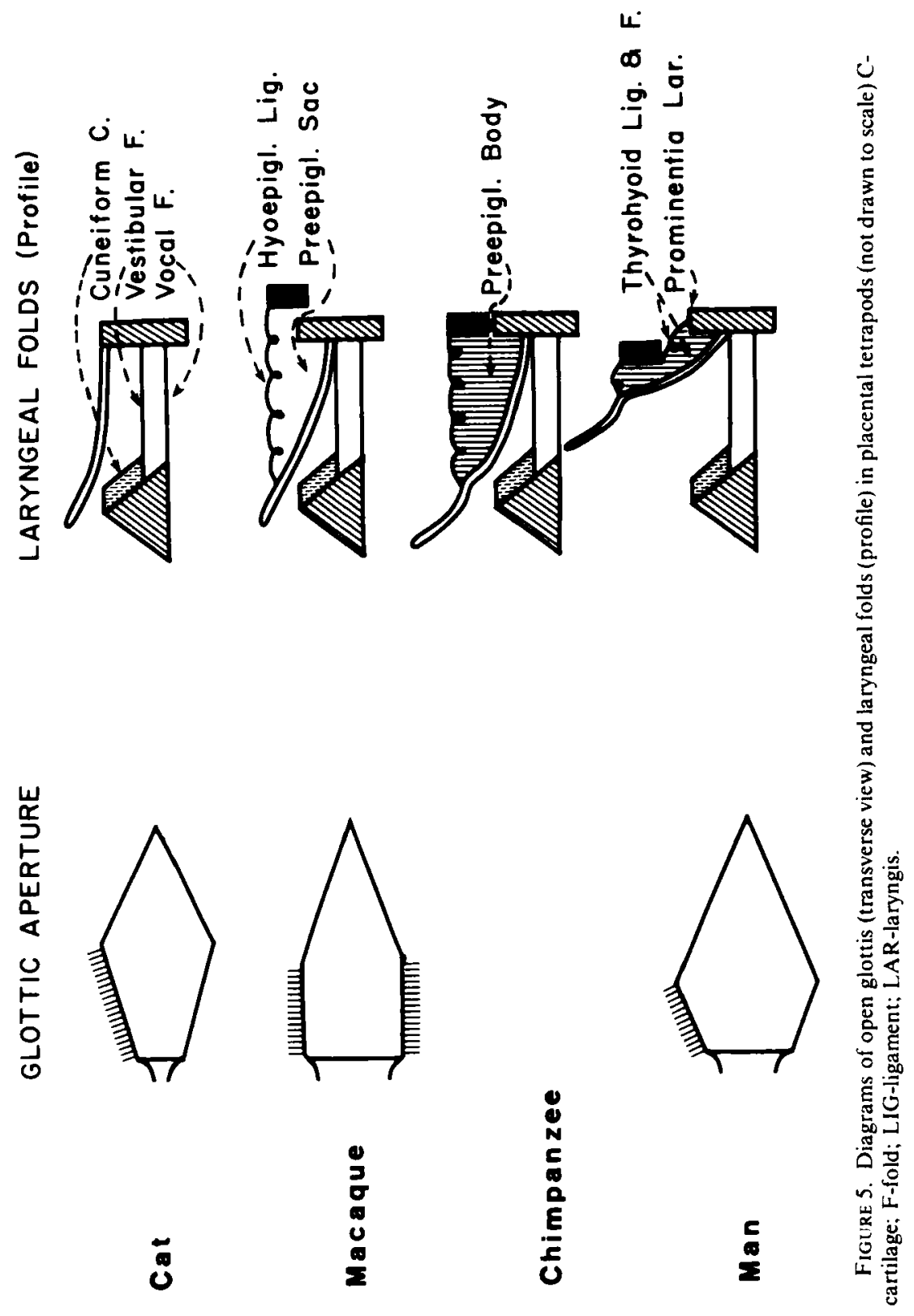


other efforts while the animal is standing on the ground. In man, however, the vestibular folds are, for the most part, solid wedges instead of flaps, and it is now known that check-valve action does not occur. ${ }^{7}$ Indeed, in man the entire plug closing the occluded larynx is solid, probably because solidity makes for firmer closure and is adaptive to intense physical effort in the orthograde habitus.

At this point I should like to ask the members of the audience to participate in a simple experiment. First, fold your arms across your chest. Second, keeping your arms folded, stand up. Thank you. Please be seated. In the effort of getting up most of you probably held your breath - that is, you closed your larynx because closure of the larynx enables one to pressurize and stiffen the trunk, in much the same way as pressurizing an air pillow stiffens the pillow. Stiffening of the trunk improves the efficiency of the attached muscles of the limbs and so facilitates effort by the limbs, such as getting up out of a chair. So, 1 repeat, effort closure of the larynx involving folding of the median thyrohyoid tissue is a usual accompaniment of forceful work effort. Orthograde manual work efforts are a highly important part of the human way of life, and their laryngeal infrastructure, including the all-solid laryngeal closing plug, therefore seems a crucial adaptation to the human ecological niche.

As noted above, unfolding of the median thyrohyoid tissue, with inspiratory descent of the laryn $x$, widens and straightens the laryngeal vestibule anteroposteriorly and reduces the resistance to air flow in this region. This too must therefore contribute appreciably to the human capacity for sustained physical manual work in the orthograde stance, a capacity that historically has been one of the bases on which human culture has been developed.

In man the mobility of the larynx and foldability of the median thyrohyoid tissue are exploited not only in work efforts but also in shaping voice formants, for the production of formants is in part.contingent on the degree of separation of the hyoid and thyroid. It therefore seems significant that this separation is relatively greater and hence more amenable to control in man than in other primates, and that the separation is markedly smaller in a newborn baby than when the child begins to learn to talk.

In summary, numerous otherwise seemingly arbitrary features of laryngeal mechanical function are intelligible as elaborations of laryngeal folding, subserving increases in laryngeal respiratory conductance, increases in voicing capacity, and proportionately increased provision for protection. In the anthropoid line they emerge in man as adaptations to the specific human ecological niche of speech and orthograde manual labor. For these reasons, it seems likely to us that the beginnings of spoken language originated contemporaneously with the distinctively human traits of the human larynx, and possibly as far back as the origin of completely orthograde locomotion.

\section{ACKNOWLEDGMENT}

We are deeply indebted to Dr. Geoffrey H. Bourne for the opportunity to cinematograph the larynx of living pongids at the Yerkes Regional Primate Center of Emory University, Atlanta, Georgia.

\section{REFERENCES}

1. Negus, V. E. 1962. The Comparative Anatomy and Physiology of the Larynx: 24. Hafner Publishing Company. New York, N.Y. 
2. Fink, B. R. 1975. The Human Larynx: A Functional Study. New York, Raven Press. New York, N.Y. 193 pp.

3. Boelaert, R. 1942. Sur la physiologie de la respiration de l'alligator mississippiensis. Arch. Int. Physiol. Biochem. 52: 57-72.

4. LAMPert, H. 1926. Zur Kenntnis des Platyrrhinenkehlkopfes. Morph. Jahrbuch 55: 607-654.

5. JORDAN. J. 1960. Quelques remarques sur la situation du larynx chez les lémuriens et les singes. Acta Biol. Med. (Gdansk) 4: 39-51.

6. Marshall, J. 1867. Outlines of Physiology, Vol. 1. p. 258. Longmans, Green. London, England

7. LindSAY, J. R. 1940. Laryngocele ventricularis. Ann. Otol. Rhinol. Laryngol. 49: 661-673. 